Research Note

\title{
RESILIENCE OF RISK SEXUAL BEHAVIOR BASED ON SEX IN THE JUNIOR HIGH SCHOOL IN SEMARANG CENTRAL JAVA
}

\author{
Dini Rakhmawati \\ Universitas PGRI Semarang \\ dini.upgris@gmail.com \\ Juntika Nurihsan \\ Universitas Pendidikan Indonesia \\ juntikanurihsan@gmail.com \\ Uman Suherman \\ Universitas Pendidikan Indonesia \\ umansuherman@yahoo.co.id
}

Resilience refers to the pattern of positive adaptation in the face of risk or difficulty (Masten \& Coatsworth, 1998; in Luthar, 2003). Adolescents who have experienced less favorable conditions risk factors tend to be more susceptible to irregularities and problem behaviors including risky sexual behavior, but there are also teenagers who have resilience in the face of adversity. Patterns teens are able to survive and recover effectively called resilience. Teens who have high resilience, will have the possibility to grow faster and happier than teens who do not have or lack the ability to bounce back from adversity (Reivich \& Shatte, 2002). The basic assumption in the study of resilience is that some individuals remain fine even though it has experienced a situation laden adversity and risky, while some other individuals fail to adapt and mired in adversity or risk a heavier again (Schoon, 2006). Low levels of resilience in adolescents will lead to vulnerability to the risks of adversity that lead to high-risk sexual behavior. gender, personal characteristics of adolescents, the situation in schools, peers, and family is something that has two sides, five things can serve as a protective factor may also be a risk factor for the development of adolescent resilience against risky sexual behavior. When adolescents can not face the risk factors that occur in the next life will result in the occurrence of risky behaviors such as risky sexual behavior.

\section{THE PRESENT STUDY}

The main objective of this study was to determine what kind of profile resilience against risk sexual behavior in junior high school students based on sex.

\section{METHOD}

\section{Partisipants}

Participants in this study is the junior high school students in 1242 a number of students (578 male, 664 female) from 5 schools in Semarang, Central Java. The method used in this research is descriptive analysis method. 


\section{Instruments}

Instruments used in this research is the scale of resilience against risky sexual behavior consists of 54 items with sub variable composed of the aspects I have, I am, and I can. Aspects I have means of support around people that support to deal with or respond positively and productively to several risk factors that allow teens to engage in sexual activity before marriage. Aspects I am means support for developing internal forces that includes selfconfidence, self-esteem, self-control and responsibility to deal with or respond positively and productively to several risk factors that allow teens to engage in sexual activity before marriage. Aspect I can means acquisition interpersonal and problem-solving skills to deal with or respond positively and productively to several risk factors that allow teens to engage in sexual activity before marriage.

Form of the scale used is a Likert scale with response options are: highly unlikely that (1) does not correspond (2), is quite appropriate (3), appropriate (4), fully compatible (5). Likert scale was developed by and is called the method of Sum-mated ratings. Basic theory is the evaluation of a person's attitude toward an object can be scaled without making a physical comparison beforehand and without prejudice to the validity (Sarwono, 2002).

\section{Procedure}

Data dissemination done directly in classes in five schools in Semarang, Central Java, the data that has been filled by the students directly collected on the researcher.

\section{Data Analysis}

All responses were imported into Excel spreadsheets and verified for completeness accuracy. Descriptive statistics data analysis was performed using the Statistical Package for Social Science (SPSS Version 20:00 for windows).

\section{RESULT AND DISCUSSION}

The tendency of the resilience of the male students, including the medium category (mean 3.21). As a dynamic, resilience male students move between categories is low (a minimum score of 1.82) to the high category (maximum score of 4.05), with a standard deviation of 0.27 . Furthermore, the resilience of female students were high (mean 3.44). As a dynamic, resilience among female students engaged in the medium category (minimum score of 2.56) to the high category (maximum score of 4.20), with a standard deviation of 0.26 . Based on the results of the deployment of the data found that resilience female students against risky sexual behavior is stronger or higher than male students resilience against risky sexual behavior.

Women have the resilience to higher-risk sexual behavior than boys. The results of this study are not consistent with research Rinaldi (2010) and Vincent (2007) which states that men have a higher resilience scores than women. Differences adjustment of men and women is influenced by biological circumstances. It is seen from the physical differences between men and women. Biological circumstances influence the behavioral differences between the sexes. According to the theory of natural selection, the division of roles is likely to encourage behavioral differences that are based on biological circumstances. Each trait inborn determine male became aggressive and smoking, and women behave as a nanny, and stay at home, while on the contrary nature of passivity male, female aggressiveness, pressed deep (Calhoun and Acocella, 1990).

The results of the study Karanci et al (1999) on the ability to adapt to the earthquake that men often use the problem-solving approach and have an optimistic attitude than women, while 
women use patterns of helplessness. Men and women have different views of perceiving risks. Results of research conducted Barend (2004) indicate that men have confidence in solving problems and believed in his abilities (competencies) to master a task or a difficult situation more positively than women. Women were more advanced aspects of affective in taking the risk, while men put forward the cognitive consideration in looking at the risks and dangers as part of life. Social circumstances affect the adjustment between men and women. Every society has the view and concept of their own behavior on the behavior of men and women and embed the benchmark (Calhoun and Acocella, 1990).

Factors that may cause the results of this study differ from the results of similar studies is resilience here related to risky sexual behavior. Several studies mention either that men are more vulnerable to risky sexual behavior than women. (Romero, Estudillo et.al, 2014; Nursal 2007; Supriati \& Fikawati 2009; Suwarni, 2009). Sexual behavioral weight proportion is higher in males than in females because it is socially more free men than women and older people tend to be more protective of women. In line with the research brodbeck, Jeannete, et al., (2010) found no difference in men and women is linked to risky sexual behavior. Adolescent sexual behavior of men is influenced by the lifestyle of hedonism and self-management skills they need to protect their risk factors. While the women are influenced by psycho-social stress and they require a high self-efficacy to protect against risk factors. Adolescent girls who have high self-efficacy was not involved or less likely to engage in risky sexual behavior in adolescents. Adolescent both men and women who receive education about the values of conduct do not engage in risky sexual behavior.
Expression of sex drive in males seem more tolerable than if it is done by women. Gender roles are part of a social role as well and not only determined by the sex of the person concerned, but by environmental and other factors. In Central Java, an area that embraces bilateral system where kinship system based on the paternal and maternal. In this system, boys and women are not distinguished in the inheritance system. Although the Java community use bilateral system in view lineage, but the relationship between men and women still tend to be patriarchal. In a family environment in Javanese, men's role as head of the family, have the power as a conduit of the decision, the breadwinners, determine the status of the family, and lead relatives. Meanwhile, the limited role of women as mothers, especially the education of children and household management, so there is a term kanca wingking (friend back) spoken husband to wife. So that women are monitored and protected than men.

\section{CONCLUSION}

There are differences in resilience against risk sexual behavior in men and women. Women have the resilience to higher-risk sexual behavior than boys. Factors that may lead to different results of this study with the results of similar research is resilience here associated with risky sexual behavior. Some research says that men are more vulnerable to risky sexual behavior than women. This study indicates that parents can be authoritative that can be warm, accepting, giving rules and norms and values clearly and wisely. Making time to hear the views of the child, as well as the independence of the young men and women are taught gradually, freedom given too early will allow teenagers trapped in a bad association. 


\section{ACKNOWLEDGEMENT}

Thanks and appreciation were the highest for Prof. Dr. Uman Suherman, M.Pd, and Prof. Dr. Juntika Nurihsan, M.Pd for his guidance in this study. Thanks also to the entire junior high school students in o8 Semarang Rayon who participated in this study.

\section{REFERENCES}

Barends, M.S. (2004). Overcoming adversity: An investigation of the role of resilience constructs in the relationship between socioeconomic and demographic factors and academic coping. Retrieved From http://ww3.uwc.ac.za/docs/\%2OLi brary/Theses/Theses\%202005\%2O 1st\%20Grad/Barends_m_s.pdf

Brodbeck, Jeannete. et.all. (2010). Sexual Risk Behavior in Emerging Adults; Gender Specific Effects of Hedonism, Psychological Distress, and Sosiocognitive Variable in 5 Year Longitudinal Study. Journal of AIDS Education and Prevention. 22 (2) 148-159. Retrieved From http://search.proquest.com

Calhoun, J.F., and Acocella, J.R. (1990). Psychology of adjusment and human relationship. New York: McGraw-Hill Publishing.

Karanci, N.A.,et.al. (1999). "Gender differences in psychological distress, coping, social support, and related variables following the 1995 Dinar (Turkey) earthquake" North America Journal of Psychology vol 1 pp 189-204. Retrieved From http://e-resources.perpusnas.go.id. 